\title{
Glass Ceiling Effect and Women Career: Determining factors in Higher Education
}

\author{
Institutions \\ * Farhat Abbas, Visiting Faculty \\ ** Nargis Abbas, Assistant Professor (Corresponding Author) \\ *** Uzma Ashiq, Lecturer
}

\begin{abstract}
The glass ceiling is a vertical segregation of women from top positions and hinders women's advancement in organizations at top positions. The study was focused to investigate the effect of the determining factors on the glass ceiling in the career advancement of women in HEIs. The study was quantitative and a multistage sampling technique was used to draw the population sample of the study. Total 154 faculty members from three public sector universities were selected. To achieve the research objectives, descriptive statistics, test of independence, and multiple regression analysis were applied to investigate the significant predictors of the glass ceiling effect. The results revealed that there was an association between the gender of the faculty member and the designation. Further, the factors "Perceived discrimination" ( $\beta=.134, p<.01)$ and "Male dominating culture' $(\beta=.295, p<$ $.001)$ were found the significantly determined the glass ceiling. Based on the findings of the study it was recommended that to control the glass ceiling effect for women, HEIs must include the blind review-based promotion and selection criteria at least for top management positions.
\end{abstract}

Keywords: Glass Ceiling, Male Dominating Culture, Perceived Discrimination, Women Career, Top Management Position, Organization Environment

\section{Introduction}

Women's advancement in organizations at top positions is hindered by the glass-ceiling phenomenon. Even in the current advanced world of business, glass-ceiling is prevailing at the workplace and women face multiple barriers in their careers due to its effects. The metaphor of glass-ceiling is initially coined by Marilyn Loden during her speech in 1978, later it was used in 1984 by Bryant in her book "The working women report". In her book, the writer analyzed the phenomenon of the glass ceiling as an Impassable barrier that keeps women away from the top positions in any organization. Besides, several pieces of research explored that the glass ceiling may occur as a metaphor for the degree and vertical segregation of women from top positions. It may have different forms like sexual and business, ethnic and minority harassment at workplace (Kretschmer, 2013; Baerts, 2011, Yamagata, 1997). Although glass-ceiling is a quite serious issue and gained the attention of the policymakers to minimize it, still women are few working at the top management level. As mentioned by McDonald \& Hite (1998) that among 1000 companies, only two women were working as chief executives i.e., $0.2 \%$ who were serving at the top positions of the company. Research has documented several factors working as hurdles in the career advancement of women and determine the glass ceiling effect. A brief preview of these factors is given below.

\section{Gender Discrimination}

Gender discrimination is an act of denying the rights, opportunity, or privilege of an individual based on sexuality. Gender, ethnicity, minority, education, and experience-based discrimination carry serious long-lasting consequences in the way of the career advancement of women. Women in developed countries are even facing workplace discrimination in pay, incentives, and promotions (Lee, 2002). Researchers revealed that women in South Asian countries are facing impediments due to gender-biased promotions trend even in high-level organizations. Men are given priority for top management positions as an administrator than women. (Jabbar \& Imran, 2013). Kang and Rawley (2005) reported that women's labor force participation ratio has increased during the last twenty years

* Department of Education, University of Sargodha

** Department of Education, University of Sargodha Email: nargis.abbas@uos.edu.pk

*** Department of Social Work, University of Sargodha Email: uzma.ashiq@ uos.ed.pk 
but only in middle management positions. Although, they have started to serve at the top management level but still very fewer in number and facing difficulties to be top-ranked instead of this middle management position (Vianen, 2002). Bain \& Cumming (2000) investigated ten universities in their study and depicted that only one woman out of every ten women was working as a professor. This percentage revealed that women's advancement even in academic professions is very low, such hurdles in the progressive career of the women are due to their gender instead of their competencies (Powell, 1994). Though, the number of women as a professor in higher education institutions have increased as compared to the past, however, their participation ratio in the decision-making boards is still insignificant (Dobele et al., 2014). In educational institutions, men even being less in number have achieved more administrative positions of Principal, Head of the department, director, dean, and Vice-chancellors, which shows that women are underprivileged and less rewarded (Raccah \& Ayalon, 2002).

\section{Organizational Environment}

A conducive work environment is the key element of increasing employees' efficiency. Biasedness in recruitment and promotion opportunities if present at the workplace affect the commitment, loyalty, and efficiency of the employees. In the case of women employees, if such biasedness, which is termed as glass-ceiling, persist in the working environment and underestimating the capabilities of the women based on their gender and deprive them of career advancement opportunities, it provokes stress and low commitment towards the organization thus affect their performance (Tiwari et al., 2019). A study conducted by Al-Manasra (2013) documented that women are facing the stereotypes in the work environment which hinder their advancement in the career, hence men are more at the top positions than women which is more visible at the upper rungs of the organization. Similarly, Valentine (2002) reported that women are facing impediments (like, women confront men ego while working as managers) more as compared to the men, while performing well in the organization. In many cultures, it's hard to accept a woman as a boss by the men's subordinates. Thus, in such cultures, women are supposed to be not fit for multi-tasking effectively.

\section{Motivation and Satisfaction}

Motivation and satisfaction are negatively associated with the discrimination which indicated that women are less motivated and satisfied in the presence of discrimination (Channar, 2011; Hwang, 2007). The employees' satisfaction can be achieved through the motivation tools like trainings. When employees are motivated, they feel happy, enjoy their work, skill, and abilities. However, in organizations, men got more opportunities for training as compared to women so there are increased chances for men to be motivated and satisfied in their workplace (Khan et al., 2012).

\section{Family Barriers}

Family barriers also work as obstacles that hinder the women's work capabilities (Batool et al., 2013). Chou et al., (2005) found that the family barrier is creating hurdles in the way of women's career advancement. They explored that due to certain family conflicts the women are unable to perform multi-dimensional job roles effectively. Domestic duties of the woman significantly consume more their time and energy as compare to their male members. Such a situation becomes even more agitated when the culture and the society also support male dominance (Livingstone et al., 2014). Researchers revealed that women are more indulged in family roles like childbearing and rearing so they are not giving preference with full energy to their duties in the workplace (Dobele et al., 2014; Manasra, 2013; Baumgartner \& Schneider, 2010; Daley, 1996).

\section{Male dominating culture}

Male dominance at top management and decision-making positions is evident world widely (Titkow, 2010). "It's birds of a feather flock together," therefore, female competency is more likely to be questioned. Longman \& Lafreniere (2012) argued that the gender imbalance in the top positions of the organizations is due to the male dominating culture. Al-Manasra (2013) conducted a study and reported that the male Executive of the organizations give preference to the male employees for the top managerial positions instead of the women because of their belief that men perform better than women. Further, Vianen \& Fischer (2002) also found that women were being provided unequal opportunities for advancement, promotion by the CEOs gender-biased approach. Hence, women in such circumstances stuck into the dead ends of the job and this little representation made the male CEOs more prominent in number as 'gentleman's club' (Bucklew et al., 2012; Rhoads \& Gu, 2012; Sanders, et al., 2008). 


\section{Perceived discrimination}

The perceived discrimination is more evident through the lens of stereotypes about the women where the man is supposed to be more productive, energetic, innovative, logical, and intellectual to serve at the top positions as compared to the woman (Radford, 1998). As a result, the women's participation ratio in top positions is not as prominent as that of the men. Such perceived barriers limit the women's participation in the economy for the development and progress of the country (Chou, 2005). Besides, Agrawal (2013) and Carrillo et al., (2013) have expressed their views that women who are more educated than men face the glass-ceiling effects more adversely. The stereotypes portray women as sensitive, weak due to kind and soft heart, submissive and less bold, and therefore they are good just for the easy tasks as compared to men who can do more challenging and risky assignments (Ali, 2014; Madichi, 2009; Valentine, 2002; Heilman, 2001).

Progress and development of any country depends upon the performance of the basic institutions. Educational institutions are among those basic institutions which are responsible to develop the potential of the youth of the country. In Pakistan, two decades back, there were 30 universities which have now increased to 218 in number. This huge number of universities will play its vital role only when the employees will have a favorable work environment. All the teachers, regardless of their gender, must have equal opportunities for career advancement otherwise there will be aggression of being neglected or discriminated, which will hinder their performance up to the expectations of the higher education set goals. Although, Higher Education Commission, Pakistan has formulated policies emphasize gender equality, several glass ceiling obstacles are yet to be addressed adequately. Therefore, the present paper investigates the determining factors of the Glass Ceiling that affect the female faculty career advancement in the education sector, especially at the university level in the context of Pakistan. Hence the current study aimed to achieve the following objective.

1. To study the gender and designation association in the higher education institutions.

2. To investigate the determining factors for class celling effects on women career advancement in Higher education institutions.

To achieve these objectives, the following statistical hypotheses were formulated;

$\mathrm{H}_{1}$ : There is no association between the gender of the respondent and designation.

$\mathrm{H}_{2}$ : Glass ceiling is not predicted by the determining factors.

\section{Research Methodology}

The current study was quantitative and a quantitative survey research design was used. The main objective of the research was to predict the effect of determining factors on the Glass ceiling phenomenon in the career advancements for women teaching in higher education institutions. The research instrument for this study was adapted from the work of Abbas (2014). The research instrument consisted of seven scales, six factors ("Perceived discrimination", "family barriers", "male culture", "organization environment", "satisfaction" and "gender discrimination") and Glass ceiling, along with the demographic categorical variables, like gender, designation, institution, work experience at current designation.

The reliability of research instrument was ensured through pilot testing. The alpha values of each scale were found between acceptable range, i.e., the Alpha value for "Perceived discrimination" was 0.87 , "family barriers" $(\alpha=0.65)$ "male dominating culture" $(\alpha=0.751)$, "organization environment" $(\alpha=0.692)$, "satisfaction" $(\alpha=0.78)$ and "gender discrimination" $(\alpha=0.77)$ and Glass ceiling at $\alpha=0.81$.

\section{Population and Sampling}

All faculty members of all public sector universities of the Punjab were the targeted population for this study. A multistage sampling technique was adopted in this research. Firstly, three universities were selected using the purposive sampling technique from the three strata of the Punjab, i.e., North, Central, and Southern Punjab based on their diverse socio-cultural grounds. Bahauddin Zakariya University, Multan from the north, University of the Punjab from central, and university of Sargodha from the southern part of the Punjab were selected. Secondly, the three most basic and common faculties present in three universities, i.e., Social science, Sciences, and Arts \& language, were selected from these universities. And lastly, a total of 154 teachers belonging to various departments of selected faculties were selected as the sample through convenient sampling. 


\section{Data Analysis and Results}

To analyze the data, frequencies and percentages were used to study the demographic information of the respondents of the study. Further, descriptive statistics and multiple regression analysis were performed to predict the effect of determining factors on the Glass-ceiling.

The distribution of respondents concerning gender showed that out of a total of 154 participants, there were 66 females $(43 \%)$ and 88 males $(57 \%)$. Sample distribution regarding universities, Next level, the age distribution of the sample shows that $96(62 \%)$ respondents were less than 35 years and 41 (27\%) belonged to the age group between 35 to 44 years the largest percentage while 15 respondents were aged above 44 years. The next variable "designation" of the faculty members showed that 74 respondents which $48 \%$ of the total sample were lecturers, whereas 21 (14\%) were working as the assistant professor. $13(8 \%)$ out of 154 faculty members were associate professor and 9 members which was the $6 \%$ of the total sample were at the designation of professor. The last categorical variable was the working experience of the respondents at the current designation. Total $29(19 \%)$ of the sample were having less than 1-year working experience, and 39(25\%) were having 1 to 2 years of experience whereas, 76(49\%) of the respondents stated more than 2 years' experience.

To test the first hypothesis, $\mathrm{H}_{1}$, that is, whether the designation is associated with the gender of the respondent, a chi-square test of independence was applied. The chi-square value showed that designation is associated at $\mathrm{p}=0.06$ \{Gender $*$ Designation: $\left.\chi_{(3)}=6.92\right\}$. Though it is not significant at a 5\% level of significance yet is enough to support that if a sample of associate professors and professor would be increased, the designation would be significantly associated with gender, that is, a man would be likely to be appointed as a professor as compare to a woman.

Next, to test the hypothesis $\mathrm{H}_{2}$, based on the second research objective of the current study, multiple regression analysis was computed. Initially, Pearson's correlation coefficients among the independent and dependent variables were calculated to investigate the interrelationship between the variables in table 1.

Table 1. Correlation coefficient among the Glass ceiling and its contributing factors

\begin{tabular}{|c|c|c|c|c|c|c|c|c|c|c|}
\hline Variables & M & SD & $\mathbf{N}$ & GC & GD & $\mathbf{S}$ & OE & FB & MC & PD \\
\hline Glass Ceiling & 3.05 & 1.05 & 154 & 1 & & & & & & \\
\hline Gender & 2.79 & .456 & 154 & $.35^{* *}$ & 1 & & & & & \\
\hline Discrimination & & & & & & & & & & \\
\hline Satisfaction & 4.92 & .985 & 154 & -.08 & $-.46^{* *}$ & 1 & & & & \\
\hline Organization & 3.86 & 1.02 & 154 & $.48^{* *}$ & $.33^{* *}$ & -.02 & 1 & & & \\
\hline Environment & & & & & & & & & & \\
\hline Family Barrier & 4.41 & 1.141 & 154 & $.28^{* * *}$ & .02 & .04 & $.25^{* *}$ & 1 & & \\
\hline Male Culture & 4.39 & 1.266 & 154 & $.74^{* * *}$ & $.36^{* *}$ & .05 & $.55^{\text {*** }}$ & $.32^{* *}$ & 1 & \\
\hline Perceived & 3.56 & 1.467 & 154 & $.57^{* * *}$ & $.42^{* *}$ & -.07 & $.68^{* * *}$ & $.23^{* *}$ & $.65^{* *}$ & 1 \\
\hline
\end{tabular}

Discrimination

Note: $* \mathrm{p}<.05 ; * * \mathrm{p}<.01$

The factors were measured on 7 points Likert scale, therefore the mean value less than 4 indicates a tendency towards "disagree" or "poor", while a value greater than 4 indicates the tendency of "agree" or "Good". For the scale "Glass-ceiling", (for example, the items were as "women face no barriers to be promoted in the organization") the mean less than $4\left(\mathrm{M}_{\mathrm{GC}}=3.05\right)$ showed that respondent tended towards the disagreement thus affirmed the presence of glass ceiling phenomenon in the HEIs. Among the determining factors, "Gender Discrimination" (it was measured with items like, "How do you see the attitude towards women by male colleagues" on the scale ranging from very poor to excellent), the mean value $\left(\mathrm{M}_{\mathrm{GD}}=2.79\right)$ indicated the presence of gender discrimination at the workplace. Further, the correlation coefficient between the GC and GD was found significant ( $\mathrm{r}$ $=0.35, \mathrm{p}<0.01)$. Moreover, "gender discrimination" also appeared significantly correlated with all other determining factors too at $\mathrm{p}<0.01$. The second-factor "Satisfaction" regarding the current designation (which was measured with the items like, "I am satisfied with my appointment, according to my qualification") was found to have a negative correlation but not significant. Similarly, it was also not found significantly correlated with other determining factors. Besides, the correlation coefficients in table 1 indicated that the factors "organizational environment", "family barriers", "male culture" and "perceived discrimination" were also found to have a significant positive correlation with the "glass ceiling". Hence significant correlation coefficient satisfied the precondition for pursuing 
multiple regression analysis. The multiple regression analysis was run by keeping "glass ceiling" as the dependent variable and remaining factors as independent variables in table 2.

Table 2. Regression analysis on Glass Ceiling and its determining factors

\begin{tabular}{|c|c|c|c|c|c|}
\hline & \multicolumn{2}{|c|}{$\begin{array}{l}\text { Determinants of Glass Ceiling } \\
\text { Model-A (Full) }\end{array}$} & \multicolumn{3}{|c|}{$\begin{array}{l}\text { Determinants of Glass Ceiling } \\
\text { Model-B }\end{array}$} \\
\hline Variable & $\begin{array}{l}\text { Regression } \\
\text { coeff }\left(\beta_{\mathrm{A}}\right)\end{array}$ & $95 \% \mathrm{CI}$ & $\begin{array}{l}\text { Regression } \\
\left(\beta_{\mathrm{B}}\right)\end{array}$ & coeff & $95 \% \mathrm{CI}$ \\
\hline Constant & 2.884 & -1.451 to 7.218 & 1.251 & & .362 to 2.86 \\
\hline Gender Discrimination & .048 & .010 to .109 & & & \\
\hline Satisfaction & -.030 & -.095 to .036 & & & \\
\hline Organization Environment & .013 & -.074 to .100 & & & \\
\hline Family Barrier & .031 & -.029 to .091 & & & \\
\hline Male dominating Culture & $.284 * * *$ & .214 to .354 & $0.295 * * *$ & & .23 to .36 \\
\hline Perceived Discrimination & $.109^{*}$ & -.010 to .227 & $0.134 * *$ & & .03 to 0.23 \\
\hline $\mathrm{R}^{2}$ & 0.58 & & 0.57 & & \\
\hline $\mathrm{F}$ & $33.41 * * *$ & & $99.14 * * *$ & & \\
\hline$\Delta \mathrm{R}^{2}$ & & & $0.57 * * *$ & & \\
\hline
\end{tabular}

Note: $* * \mathrm{p}<.01 \& * * * \mathrm{p}<.001$

The regression model-A was run with all six causal factors and the "glass ceiling" variable as the dependent variable. In the ANOVA table, that test the hypothesis of the significance of the model, the value of F-statistic was found significant $(F(6,147)=33.41, p<.001)$. Hence the model was significantly predicting the variable "Glass ceiling". In column 1 of the model-A, the regression coefficients were measured against each factor. The non-significant regression coefficients of four factors "gender discrimination", "satisfaction", "org. Environment" and "family barriers showed that these were not appeared as the significant predictors of "glass ceiling" at 5\% level of significance. However, the significant regression coefficient of factor "Male dominating culture" demonstrated that it was a significant predictor of the glass ceiling $(\beta=.284, \mathrm{p}<.001)$. It shows that for each unit increase in male dominating culture, the glass ceiling effect is increased by 0.28 units. Further, the regression coefficient of "perceived discrimination" was also found significant at a $5 \%$ level of significance $(\beta=.109, \mathrm{p}<.05)$, which meant that the factor "perceived discrimination" was significantly determining the glass ceiling effect. If perceived discrimination is increased 1-unit (or $100 \%$ ), the glass ceiling effect increased by 0.11 units (or $11 \%$ ). Further, the $\mathrm{R}^{2}$ which explains the variance in the dependent variable explained the independent variables in the model (Field, 2013), which was found 0.58 . Theoretically, it indicated that the model-A with six determining factors together explained $58 \%$ of the variance in the glass ceiling.

In the next step, to study the model with the significant factors only, multiple regression analysis was rerun with "Male dominating culture" and "perceived discrimination" as the causal variables and glass ceiling as the outcome variable in Model-B in table 2. The F value showed that this model was significantly predicting the glass ceiling effect $(F(6,147)=99.14, p<.001)$. Besides, the magnitude of the regression coefficients of both predictors was little increased. In the Model-B too, the causal variable "Male dominating culture" was significantly predicting the glass ceiling effect for women in their career advancement $(\beta=.295, \mathrm{p}<.001)$. In model-B, a 1 -unit increase in male dominating culture increases .295 units of glass ceiling effect on the women career advancement. Similarly, the other causal variable "perceived discrimination" was also found a significant predictor of "glass ceiling" at a $1 \%$ level of significance $(\beta=.134, p<.01)$. The beta value shows that the glass ceiling for women increases by .134 units, with every unit increase in perceived discrimination. Moreover, the total variance in the "glass ceiling" explained by these two factors was found $0.57\left(\mathrm{R}^{2}\right.$ $=0.57$ ), which indicated that in both models, $57 \%$ of the variance was explained by these two factors only.

\section{Discussion}

The under-representation of women in top rank positions pinpoints the glass ceiling phenomenon in their career advancement in higher education institutions. This study identified that gender discrimination, organization environment, family barrier, perceived discrimination, male dominating culture were significantly positively correlated with the glass ceiling which indicated that magnitude of these variables if increase, the effect of glass ceiling also increases significantly. While motivation and job satisfaction was found significantly negatively correlated with a glass ceiling which revealed 
the fact that a high level of motivation and satisfaction at the workplace decreases the magnitude of the glass ceiling. These findings are aligned with the earlier studies mentioned in the literature that males and females are treated differently even at higher educational institutions. Most notably, these discriminations are more observed for the women at top ranks rather than middle or low rank (Maume,1999). Further findings of the current study revealed that, among all determining factors, perceived discrimination and male dominating culture were found significant predictors of the glass ceiling. It indicated that the university, which is responsible for preparing human capital as the future of the nation, are not providing the gender-balanced opportunities for career advancement.

\section{Conclusion and recommendations}

The glass ceiling phenomenon indicates the workplace discriminations due to certain determining factors that initiate gender biasedness and hinder the women's career advancement. Women are more than fifty percent of the total population in Pakistan. Thus, if the glass ceiling limits the women's opportunities for workforce participation, resultantly the process of economic development at the national level would be slow down.

The current study determined the factors of the glass ceiling phenomenon in the career advancement of women in HEIs. The results are aligned with the findings of Channar (2010) and Madichi (2009), which showed that gender discrimination has a negative effect on the job promotion of women. Similarly, Wahab, (2004); Yousefy and Baratali (2011) documented that in recent years, although the women ratio has increased in the workforce however still a gender gap exists in the top management level in the education sector. Likewise, the results are also supported by the study of Yasmeen (2005), who stated women disparities concerning economic rights.

Hence, for the glorious and prosperous future of the nation, equal opportunities for career advancement are the need of the hour. The productivity of the institutions can gain momentum by the increased participation of the women at top position levels. This will diminish the feelings of discrimination, stress which in result, improve the job commitment and job performance of the women (Rodriguez, 2013). Therefore, it is suggested that equal and fair opportunities for career advancement should be provided regardless of sex as also documented by Katz and La Van, (2004); Orife and Chaubey (2001). It is further recommended that the promotions should be based on the blind review process based on qualification, skill, competencies, and experience of the employees by the selection or promotion board. This can be done by the initial review of the documents submitted by the employee with a secret code without mentioning the name and gender of the candidate. Similar criteria must be followed for awarding rewards and incentives.

\section{References}

Agrawal, T. (2013). Are There Glass-Ceiling and Sticky-Floor Effects in India? An Empirical Examination. Oxford Development Studies, 41(3), 322-342. doi: 10.1080/13600818.2013. 804499

Al-Manasra, E. A. (2013). What Are the "Glass Ceiling" Barriers Effects on Women Career Progress in Jordan? [Article]. International Journal of Business \& Management, 8(6), 40-46. doi: 10.5539/ijbm.v8n6p40

Baerts, A., Deschacht, N., \& Guerry, M.-A. (2011). The Role of the Partner in Promotions to Top Positions in Belgium. [Article]. European Sociological Review, 27(5), 654-668.

Bain, O., \& Cummings, W. (2000). Academe's Glass Ceiling: Societal, Professional-Organizational, and Institutional Barriers to the Career Advancement of Academic Women. Comparative Education Review, 44(4), 493-514.

Baumgartner, M. S., \& Schneider, D. E. (2010). Perceptions of Women in Management: A Thematic Analysis of Razing the Glass Ceiling. Journal of Career Development, 37(2), 559-576. doi: 10.1177/0894845309352242

Bell, M., McLaughlin, M., \& Sequeira, J. (2002). Discrimination, Harassment, and the Glass Ceiling: Women Executives as Change Agents. Journal of Business Ethics, 37(1), 65-76. doi: 10.1023/a:1014730102063

Buckalew, E., Konstantinopoulos, A., Russell, J., \& Seif, E.-S. (2012). The Future of Female CEOs and Their Glass Ceiling. Journal of Business Studies Quarterly, 3(4), 145-153.

Carrillo, P., Gandelman, N., \& Robano, V. (2013). Sticky floors and glass ceilings in Latin America. The Journal of Economic Inequality, 12(3), 339-361. doi: 10.1007/s10888-013-9258-3

Channar, Z. A., Abbassi, Z., \& Ujan, I. A. (2011). Gender discrimination in the workforce and its 
impact on the employees. Pakistan Journal of Commerce and Social Sciences (PJCSS), 5(1), 177-191.

Chou, W.-C. G., Fosh, P., \& Foster, D. (2005). Female Managers in Taiwan: Opportunities and Barriers in Changing Times. Asia Pacific Business Review, 11(2), 251-266. doi: $10.1080 / 1360238042000291153$

Daley, D. M. (1996). Paths of glory and the glass ceiling: Differing patterns of career advancement among women and minority federal employees. Public Administration Quarterly, 20(2), 143162.

Dobele, A. R., Rundle-Thiele, S., \& Kopanidis, F. (2014). The cracked glass ceiling: equal work but unequal status. Higher Education Research \& Development, 1-13. doi: 10.1080/ 07294360.2013 .841654

Guadagno, R., \& Eno, C. (2010). Cracks in the Glass: Working Women's Challenges in the New Millennium. Sex Roles, 63(11-12), 894-896. doi: 10.1007/s11199-010-9822-2

Yousefy, A., \& Baratali, M. (2011). Women, Employment and Higher education schoolings. Procedia, Social and Behavioral Sciences, 15, 3861-3869. doi:10.1016/j.sbspro.2011.04.386

Hwang, M. J. (2007). Asian Social Workers' Perceptions of Glass Ceiling, Organizational Fairness and Career Prospects. Journal of Social Service Research, 33(4), 13-24. doi: 10.1300/ J079v33n04_02

Jabbar, A., \& Imran, A. (2013). Perception of glass ceiling in the educational institution: An evidence from Pakistan. World Applied Sciences Journal, 23(5), 628-634.

Jellal, M., Nordman, C. J., \& Wolff, F.-C. (2008). Evidence on the glass ceiling effect in France using matched worker-firm data. [Article]. Applied Economics, 40(24), 3233-3250. doi: 10.1080/ 00036840600994070

Kang, H.-R., \& Rowley, C. (2005). Women in Management in South Korea: Advancement or Retrenchment? Asia Pacific Business Review, 11(2), 213-231. doi: 10.1080/13602380 42000291171

Katz, M., \& LaVan, H. (2004). Legal Protection from Discrimination Based on Sexual Orientation: Findings from Litigation. Employee Responsibilities and Rights Journal, 16(4), 195-209. doi: 10.1007/s10672-004-4636-4

Khan, M. M., Rehman, Z-u., \& Dost, M. K. B. (2012). The Glass Ceiling vs. Employee performance impact on employees' satisfaction level in the organization. Singapore Journal of Business Economics and Management studies. 1(3), 59-75. https://www.singaporeanjbem.com/pdfs/ SG_VOL_1_(3)/6.pdf

Kretschmer, H., \& Kretschmer, T. (2013). Gender bias and explanation models for the phenomenon of women's discriminations in research careers. Scientometrics, 97(1), 25-36. doi: 10.1007/s11192-013-1023-7

Lee, S. M. (2002). Do Asian American Faculty Face a Glass Ceiling in Higher Education? American Educational Research Journal, 39(3), 695-724. doi: 10.3102/00028312039003695

Livingstone, D.W. \& Pollock, K., \& Raykov, M. (2014). Family Binds and Glass Ceilings: Women Managers' Promotion Limits in a 'Knowledge Economy'. Critical Sociology. 42(1), 145-166. $10.1177 / 0896920514532663$.

Longman, K. A., \& Lafreniere, S. L. (2012). Moving beyond the Stained Glass Ceiling: Preparing Women for Leadership in Faith-Based Higher Education. Advances in Developing Human Resources, 14(1), 45-61. doi: 10.1177/1523422311427429

Madichie, N. O. (2009). Breaking the Glass Ceiling in Nigeria: A Review of Women's Entrepreneurship. Journal of African Business, 10(1), 51-66. doi: 10.1080/15228910 802701361

Maume, D. J. (1999). Glass Ceilings and Glass Escalators: Occupational Segregation and Race and Sex Differences in Managerial Promotions. Work and Occupations, 26(4), 483-509. doi: $10.1177 / 0730888499026004005$

McDonald, K. S., \& Hite, L. M. (1998). Exploring the Glass Ceiling: An Exploration of Gender Differences in Management-Development Experiences. Journal of Management Education, 22(2), 242-254. doi: 10.1177/105256299802200211

Orife, J. N., \& Chaubey, M. D. (2001). Models of Equal Employment Opportunity. Journal of African Business, 2(3), 93-113. doi: 10.1300/J156v02n03_06 
Powell, G. N., \& Butterfield, D. A. (1994). Investigating the "Glass Ceiling" Phenomenon: An Empirical Study of Actual Promotions to Top Management. The Academy of Management Journal, 37(1), 68-86. doi: 10.2307/256770

Radford, J. (1998). Gender and Choice in Education and Occupation. Routledge London and New York.

Rhoads, R., \& Gu, D. (2012). A gendered point of view on the challenges of women academics in The People's Republic of China. Higher Education, 63(6), 733-750. doi: 10.1007/s10734-0119474-3

Sanders, K., Willemsen, T., \& Millar, C. J. M. (2009). Views from Above the Glass Ceiling: Does the Academic Environment Influence Women Professors' Careers and Experiences? Sex Roles, 60(5-6), 301-312. doi: 10.1007/s11199-008-9547-7

Titkow, A. (2010). Do Men Have Their Own Glass Ceiling? Polish Sociological Review, 172, 391-409. Retrieved December 20, 2020, from http://www.jstor.org/stable/41275171

Valentine, S. (2001). Men and Women Supervisors' Job Responsibility, Job Satisfaction, and Employee Monitoring. Sex Roles, 45(3-4), 179-197. doi: 10.1023/a:1013549710711

Van Vianen, A. E. M., \& Fischer, A. H. (2002). Illuminating the glass ceiling: The role of organizational culture preferences. Journal of Occupational and Organizational Psychology, 75(3), 315-337. doi: 10.1348/096317902320369730

Wahab, Z. (2004). Women's access to higher education in an urban center of Pakistan (Doctoral Dissertation, Hamdard University of Karachi). http://prr.hec.gov.pk/jspui/handle/123456789/ 4655

Yamagata, H., Yeh, K. S., Shelby, S., \& Dodge, H. (1997). Sex Segregation and Glass Ceilings: A Comparative Statics Model of Women's Career Opportunities in the Federal Government over a Quarter of a Century. American Journal of Sociology, 103(3), 566-632. doi: $10.1086 / 231251$ 